\title{
Advanced Metabolic Engineering Approaches and Renewable Energy to Improve Environmental Benefits of Algal Biofuels: LCA of Large-scale Biobutanol Production with Cyanobacteria Synechocystis PCC6803
}

\author{
Daniela Villacreses-Freire ${ }^{1}$ (i) $\cdot$ Franziska Ketzer $^{1} \cdot$ Christine Rösch $^{1}$
}

Received: 26 May 2021 / Accepted: 17 August 2021

(c) Springer Science+Business Media, LLC, part of Springer Nature 2021

\begin{abstract}
With modern genetic engineering tools, microorganisms can become resilient green cell factories to produce sustainable biofuels directly. Compared to non-engineered algae and cyanobacteria, the photon conversion efficiency can be significantly increased. Furthermore, simplified harvesting processes are feasible since the novel microorganisms are excreting the biofuels or their precursors continuously and directly into the cultivation media. Along with higher productivity and direct product harvesting, it is expected that environmental benefits can be achieved, especially for climate protection. A life cycle assessment (LCA) for biobutanol production with the genetically engineered cyanobacteria Synechocystis PCC6803 is performed to test this hypothesis. A prospective and upscaled approach was applied to assess the environmental impacts at large-scale production (20 ha plant) for better comparability with conventional butanol production. The LCA results show that the engineering of microorganisms can improve the environmental impact, mainly due to the higher productivity compared to non-engineered cyanobacteria. However, the nevertheless high electricity demand required for the cultivation and harvesting process overcompensates this benefit. According to the scenario calculations, a more favourable climate gas balance can be achieved if renewable electricity is used. Then, greenhouse gas emissions are reduced to $3.1 \mathrm{~kg} \mathrm{CO}$ eq/ $/ \mathrm{kg}$ biobutanol, corresponding to $20 \%$ more than the fossil reference: $\left(2.45 \mathrm{~kg} \mathrm{CO}_{2}\right.$ eq. $/ \mathrm{kg}$ 1-butanol). The results indicate the importance of genetic engineering and the energy transition towards renewable electricity supply to take full advantage of the environmental potential of microorganisms as future green cell factories for sustainable biofuel production. Besides, the necessity of developing different scenarios for perspective and upscaled LCA for a fairer comparison with mature reference technologies is demonstrated.
\end{abstract}

Keywords Life cycle assessment $\cdot$ Upscaling $\cdot$ Cyanobacteria $\cdot$ Biobutanol $\cdot$ Scenario approach

\section{Introduction}

Technical and social innovations are needed to replace fossil energy consumption with renewable energy to combat climate change. The focus is on the transportation sector, as the savings potential realised here is insufficient to achieve the ambitious political goals for climate-neutral transportation by 2050 . By the year 2020, $10 \%$ of the energy used in

Daniela Villacreses-Freire

danivill86@gmail.com

1 Institute for Technology Assessment and Systems Analysis, Karlsruhe Institute of Technology, PO Box 3640, 76021 Karlsruhe, Germany the transport sector of every EU country should come from renewable energy sources such as biofuels [1]. As biofuels create less greenhouse gas emissions than fossil fuels, this will help the EU meet its long-term target of reducing greenhouse gas emissions by $85-90 \%$ (compared to 1990) by 2050 [1]. Technological innovations such as fuel production with genetically engineered microalgae and cyanobacteria had to be evaluated at the earliest possible stage of development, especially concerning their climate and environmental compatibility to inform, advise and guide decision-makers in research, politics and industry. While first risk [2] and acceptance studies [3], as well as a techno-economic analysis [4] have already addressed this issue, the probable environmental implications of this technology have so far not 
been analysed or quantified in LCA studies in the literature [5], which underlines the novelty of the present work.

Biofuels from microalgae are innovative and comply with the EU sustainability criteria for biofuels and bioliquids [6, 7]. They are cultivated in closed technical systems on industrial or marginal land and can be grown with seawater and nutrients from organic waste streams, such as from biogas plants. Microalgae and cyanobacteria have been investigated according to their feedstock potential for producing sustainable biofuels $[1,6]$. However, studies show that algae biofuel production is not yet environmental and economically feasible, and further R\&D efforts are needed to increase productivity and efficiency and reduce production costs [4].

Microalgae can be used to produce different fuels: biodiesel [8], biomethane and biobutanol [9] or hydrogen [10, 11]. For large-scale energy production, open ponds are considered to be the most appropriate approach. However, this technology is not innovative and can offset some of the environmental advantages of microalgae [12-14]. That is why there are combined and interdisciplinary approaches towards innovative processes for producing third-generation algal biofuels.

One of these approaches is the genetic engineering of microalgae and cyanobacteria to speed up strain selection and optimisation and increase productivity significantly. Beyond that, biologists and process engineers aim to produce algal fuel precursors or fuels that can pass the cell wall (such as biobutanol). Then, the fuel is excreted into the culture media from which it can be harvested [15-17]. In that way, the microalgae or cyanobacteria do not need to be destroyed for harvesting the biofuel precursors but can continue growing. This way, the biofuel production remains under steady conditions, and fewer resources are required for recultivating the microorganisms. This so-called "milking"process facilitates and reduces the energy demand for the ongoing recultivation of the microalgae and the harvesting step, the dewatering as well as fractionation of the algae biomass.

This paper assesses the environmental impacts of 1-butanol (referred to here as biobutanol) by the genetically engineered cyanobacteria Synechocystis PCC6803. Biobutanol has many advantages over other alternatives, including its low vapour pressure, high energy density and ability to replace gasoline directly [18]. The higher energy density of butanol than ethanol allows for better fuel efficiency in vehicles, giving the consumer better gas mileage [19]. Besides, the physical properties of butanol allow for direct use (fuel blend with gasoline in higher proportion than ethanol) in conventional engines without significant engine modifications [20].

The cyanobacteria Synechocystis PCC6803 was selected since it has the highest productivity among different microalgae and cyanobacteria tested at lab and pilot scale. The release of the fuel precursor into the culture medium could reduce the energy demand related to harvesting and biomass fractionation. Consequently, promising outcomes are expected concerning the energy balance compared to conventional microalgae fuel production, which often comes with low energy return on investment (EROI). A review by Ketzer et al. [21] provided insights into 16 different studies with similar frame conditions. Even though a high variability could be observed, evidence for negative net energy balance for microalgae biomass fuel production was found.

Carmona-Garcia et al. [22] have highlighted the considerable advantages of biobutanol production using microorganisms against the catalytic route. Considering conventional acetone-butanol-ethanol (ABE) fermentation, several critical aspects, e.g. recovery and purification methods, influencing the energy return on investment (EROI) similar to in the presented biobutanol production [23-27]. Nevertheless, Garcia et al. [28] highlight the potential of improving the overall efficiency of the fermentation by adequate pretreatment of the raw material, altering the fermentation process itself, product recovery and purification processes. They recommended efforts on genetic engineering, materials science and process and bioprocess engineering to overcome the efficiency obstacle in biobutanol production.

The life cycle assessment (LCA) approach is a powerful tool to investigate a product according to its environmental impacts along the entire life span. By applying LCA, this paper gives insights into the opportunities and challenges of biobutanol production and shows the ecological bottlenecks and hotspots of the production process. For a fair comparison with fossil-based 1-butanol production, an upscaling procedure to model and assess algal fuel production with genetically engineered (GE) cyanobacteria at a large scale was developed and applied. Since political framing and future developments can significantly impact the environmental performance of algal technologies, the LCA was conducted against the background of different scenarios.

\section{Methodology}

\section{Goal and Scope}

The LCA methodology was chosen not only considering its relevance as a scientific assessment but also the current significant impact of LCA in other issues, such as policy development, system, component design, authorisation and permissions, and consensus-building [29]. Hence, the goal of this LCA is to provide a consistent understanding of the biobutanol production process related to environmental issues. This LCA model was developed together with biologists, technical and process engineers. Figure 1 shows the system boundaries and the considered process flow. One of 


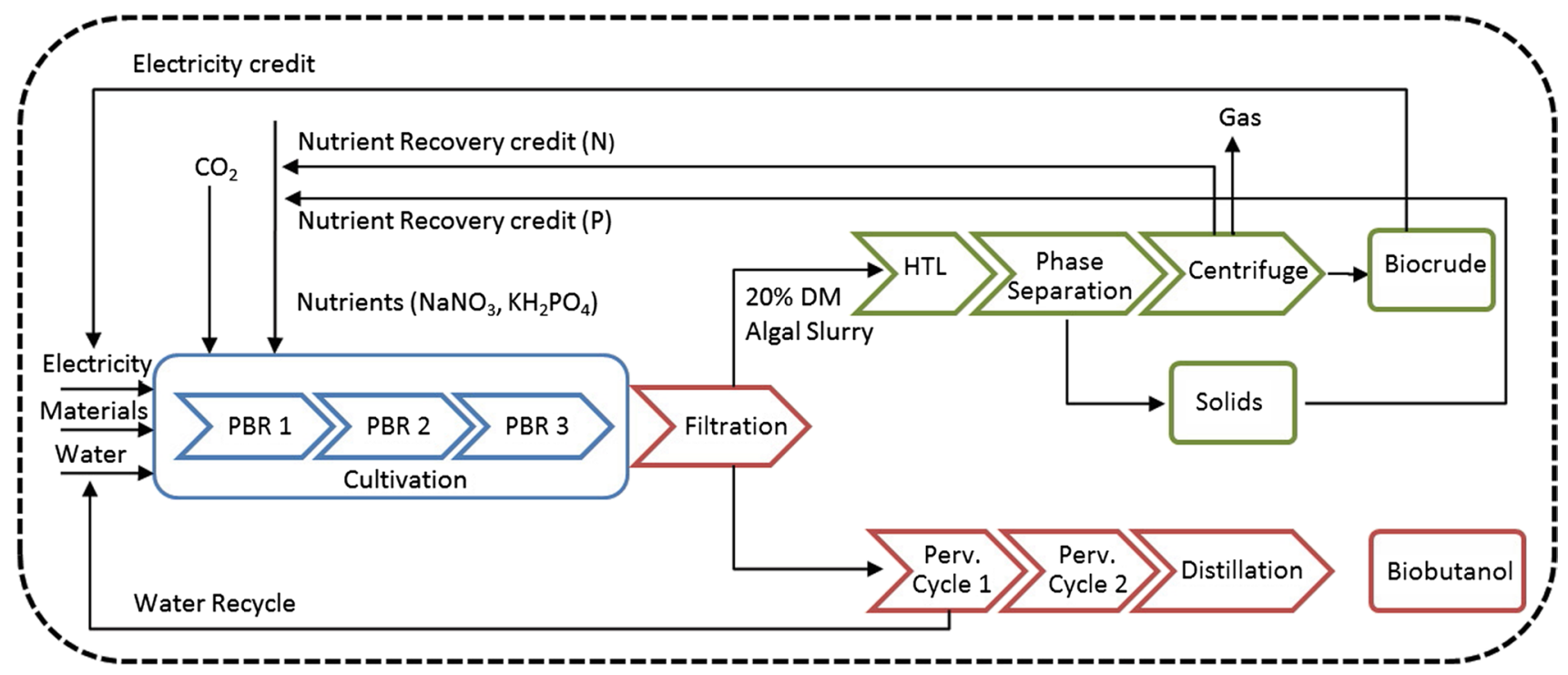

Fig. 1 LCA system boundaries and process flow of biobutanol production with the cyanobacteria Synechocystis PCC6803 (PBR, photobioreactor; HTL, hydrothermal liquefaction; Perv., pervaporation; DM, dry matter; N, nitrogen; P, phosphorus)

the main characteristics of this novel technology is the possibility to produce fuel precursors that are being excreted into the culture media from which they are harvested afterwards without destroying the cell wall (so-called "milking process").

Emerging technologies have considerable potential for improvements, e.g. by applying economies of scale [30], as already successfully shown for other biofuel technologies [31]. The first step of biobutanol production is continuous cultivation of Synechocystis PCC6803 and its upscaling by considering three consecutive photobioreactors (PBR): pre-inoculation (PBR 1), inoculation (PBR 2) and production (PBR 3). After harvesting, the product is filtered and separated into two phases: a biobutanol-rich medium (ca. 65 vol. \%) and the biomass slurry (ca. 35 vol. \%). The biobutanol-rich medium is recovered by a pervaporation and distillation process. The biomass slurry (with $20 \%$ dry matter (DM) content) is valorised by hydrothermal liquefaction (HTL), separation and centrifugation processes and converted into four product streams. All these processes were considered in the LCA.

Microalgae biofuel technology is still at an early stage of development compared to other biofuels [5, 32]. According to the literature, a significant pending issue for algal biofuel LCA prevails on the input data and its characteristics, detail, and quality [29]. Consequently, for comprehensive data acquisition from lab- and pilot-scale installations, a systematic and elaborated questionnaire was developed to collect the required data and information on process design, technology and equipment to model and calculate the LCA from well-to-tank. Intense and close personal exchange, virtual meetings and email correspondence complemented the discussion on the constructed data framework and proposed assumptions to bridge the data gaps. By this, as much information and original data for the LCA inventory as possible were gathered, analysed and adapted. Based on this inventory completed by data from other projects, literature and the Ecoinvent database 3.2 [33], the environmental impact assessment (EIA) for a pilot-scale system (pre-study) was conducted. The production process was modelled with the open-source software OpenLCA 1.9.

The ecoinvent database comprises raw material extraction as well as the assembly to pre-products, e.g. borosilicate tubes. According to Tillmann et al. [34], practical aspects limit the LCA system's extent and complexity. Among these aspects, the availability of data is crucial. For that reason, inputs, such as raw materials, for preparing the production site, machine abrasion and disposal, are defined to be outside this system's boundaries (see Fig. 1). Data acquisition for these steps would have been challenging and not the core of the LCA goal to assess the "butanol milking process" at low TR1 level. In addition, transport, storage and end-of-life options are expected to play only a minor role within the overall impacts.

The functional unit is defined as the production of $1 \mathrm{~kg}$ of "engine-ready" biobutanol, which can be used directly as fuel for a combustion engine. To evaluate a specific process, it must refer to conventional fossil-based production pathways. Here, the ecoinvent database process named "Butanol production from hydroformylation of propylene" was selected to compare the results to biobutanol produced by the cyanobacteria. For quantifying the life cycle impacts, the recommendations of the International Reference Life Cycle Data System (ILCD) Handbook 2011 were followed 
[35]. This impact assessment method was developed by the European Commission and is implemented in the OpenLCA software. There are 16 midpoint categories, classified into three types and ranked according to their reliability. Thereof, six categories were selected, considered the most relevant ones for the process analysed (Table 1).

Midpoint categories classified as "I" deliver recommended and satisfactory results. Among these, well-known and commonly used categories like climate change and particulate matter formation were chosen. Freshwater eutrophication and mineral resource depletion were chosen from category "II" because of the expected impact of materials' and fertilisers' upstream production inputs used in a large-scale production system. Since this category is recommended but needs to be improved, the reliability of the results is not as high as those of the category "I". The indicators considered from category "III" are water resource depletion and land use. They were selected based on the relevance of water demand for microalgae cultivation and industrial land occupation in the upscaled system [5]. However, these "III"-ranked categories are less recommended and need to be applied with caution.

\section{Prospective Process Upscaling}

Following the typical methodology of ex-ante prospective LCA [36], the insights are drawn from the lab- and pilotscale results were used to design and model a large-scale production plant (20 ha). Therefore, the best productivities achieved at lab scale and upscaling the process were used to analyse whether an optimised, large-scale system has lower environmental impacts per unit (kg biobutanol) produced than the pilot scale (Table 2).

Biobutanol productivities of Synechocystis PCC 6803 were extrapolated from lab-scale experiments by Uppsala University (Sweden) and Imperial College London (UK). Average butanol productivity of $600 \mathrm{mg} / \mathrm{L} /$ day in year-round productions (360 days) was assumed [40]. Since genetically modified cyanobacteria were used in a closed PBR system, a continuous production process was assumed to keep the risk of leakage low and prevent exposure and cross-breeding, as shown in the literature [12, 13].

The system boundaries of the pilot scale are based on a PBR installation of the existing pilot plant in Lisbon. After analysing different reactor types, the unilayer horizontal tubular (UHT) PBR was chosen as the best available cultivation technology since this reactor proved to be more efficient in terms of productivity as well as material and energy inputs than a multilayer horizontal tubular (MHT) PBR (Guerra, T., personal communication, January 23, 2019). Scenarios with upscaled production systems for algae-based biobutanol production (20 ha) were modelled and calculated to assess the environmental impacts prospectively and improve comparability.

\section{Cultivation}

Commercial large-scale microalgae cultivation is almost entirely performed using open raceway ponds in the batch mode and producing other products than biofuels [13]. The theoretical process design for this prospective and upscaled system is based on the concept and design of a cultivation

Table 1 Selected ILCD midpoint impact categories [35]

ILCD midpoint application

\begin{tabular}{|c|c|c|c|}
\hline Impact category & Default LCIA method & Indicator & Classification \\
\hline Climate change & $\begin{array}{l}\text { ILCD 2011: baseline model of } 100 \text { years } \\
\text { of IPCC }\end{array}$ & $\begin{array}{l}\text { Radiative forcing as Global Warming } \\
\text { Potential (GWP 100) }\end{array}$ & I \\
\hline Particulate matter/respiratory inorganics & $\begin{array}{l}\text { RiskPoll model (Rabl and Spadaro, 2004) } \\
\text { and Greco et al. } 2007\end{array}$ & $\begin{array}{l}\text { Intake fraction for fine particles }(\mathrm{kg} \\
\left.\mathrm{PM}_{2.5}-\mathrm{eq} / \mathrm{kg}\right)\end{array}$ & \\
\hline $\begin{array}{l}\text { Resource depletion, mineral, fossil, and } \\
\text { renewable (depletion of renewable } \\
\text { resources is included in the analysis, but } \\
\text { none of the analysed methods is mature } \\
\text { for the recommendation) }\end{array}$ & $\begin{array}{l}\text { CML } 2002 \\
\text { (Guinée et al. 2002) }\end{array}$ & Scarcity & II \\
\hline Eutrophication, aquatic & $\begin{array}{l}\text { EUTREND model } \\
\text { (Struijts et al. 2009b) as implemented in } \\
\text { ReCiPE }\end{array}$ & $\begin{array}{l}\text { Fraction of nutrients reaching freshwater } \\
\text { end compartment }(\mathrm{P}) \text { or marine end } \\
\text { compartment }(\mathrm{N})\end{array}$ & \\
\hline Land use & $\begin{array}{l}\text { Model-based on Soil Organic Matter } \\
\text { (SOM) } \\
\text { (Milà i Canals et al. 2007b) }\end{array}$ & Soil organic matter & III \\
\hline Resource depletion, water & $\begin{array}{l}\text { Model for water consumption as in Swiss } \\
\text { Ecoscarcity } \\
\text { (Frischknecht et al. 2008) }\end{array}$ & $\begin{array}{l}\text { Water use related to the local scarcity of } \\
\text { water }\end{array}$ & \\
\hline
\end{tabular}


Table 2 Assumptions for the prospective upscaling of the LCA model

\begin{tabular}{|c|c|c|c|}
\hline & Lab & Upscale & Assumptions \\
\hline Productivity (mg/l/day) & $\begin{array}{l}50 \text { (weighted average of } \\
\text { two strains) })^{\mathrm{a}}\end{array}$ & $600^{\mathrm{d}}$ & Highest productivity achieved under lab conditions \\
\hline Biobutanol concentration in PBR $[\mathrm{g} / \mathrm{l}]$ & 1 & 2.65 & Measured biobutanol concentration \\
\hline Biomass/biobutanol ratio & 1:1 [own assumption] & $0.35: 0.65^{\mathrm{d}}$ & \\
\hline \multicolumn{4}{|l|}{ Energy use [kWh/ kg biobutanol] } \\
\hline - Cultivation & $483^{\mathrm{a}}$ & 23 & Upscale by flow ${ }^{b}$ \\
\hline \multicolumn{4}{|l|}{ - Separation/pervaporation: } \\
\hline -Heating and cooling & $86[26]$ & 109 & Upscale by flow ${ }^{c}$, energy saving applied ${ }^{\mathrm{e}}$ \\
\hline -Pumping & $18[26]$ & 23 & Upscale by flow $^{\mathrm{c}}$, energy saving applied ${ }^{\mathrm{e}}$ \\
\hline Hydrothermal liquefaction [ $\mathrm{kWh} / \mathrm{kg}$ biobutanol] & n.a & 0.84 & Upscale by flow ${ }^{\mathrm{b}}[37,38]$ \\
\hline
\end{tabular}

${ }^{\mathrm{a}}$ Guerra, T. (personal communication, March 28, 2017). ${ }^{\mathrm{b}}$ Guerra, T. (personal communication, September 19, 2018). ${ }^{\mathrm{c}}$ According to Lauersen et al. [39]. ${ }^{\mathrm{d}}$ According to Boatman et al. [40]. ${ }^{\mathrm{e}}$ According to Liu et al. [37]

unit at a pilot scale, with a continuous process and daily product (ethanol) harvesting. Continuous cultivation is considered a more efficient path for producing biofuels [41]. Based on this process, confidential information on the upscaling of the UHT-PBR system for ethanol was provided by Guerra, T. (personal communication, July 3, 2018). The land occupied by the reactor was assumed to be classified as an industrial area and used for 20 years to match the system and equipment lifespan. For a final cultivation scale, three consecutive production volumes have to be achieved: preinoculation (PBR 1), inoculation (PBR 2), and production (PBR 3). The occupied area and the associated volume and number of units are listed in Table S 1 in the supplement; the description of the system is given in Table 3 .

\section{Separation and Harvesting}

The recovery of biobutanol from dilute mixtures represents a bio-technical challenge in the photoautotrophic production of excreted biofuels which has not yet been addressed satisfyingly. The most suitable and cost-effective microalgal harvesting method is a constant matter of research [13]. Recently, four of the most promising butanol separation technologies (distillation, pervaporation, gas stripping and ionic liquid extraction) were assessed, concluding that, at present, it is necessary to make a compromise between energy requirement and operating costs [26]. Based on these findings for the prospective upscaled LCA model, the pervaporation technique to separate the biobutanol from the cyanobacteria culture broth was selected. Following the cultivation process in the UHT-PBR, the product flow was separated using a polypropylene microfilter (Boatman, T., personal communication, January 7, 2019) into two phases: a biobutanol-rich medium (ca. 65 vol.\%) and the biomass slurry (ca. 35 vol. \%) [40]. Consequently, the pervaporation system was implemented with a temperature of $60{ }^{\circ} \mathrm{C}$, including energy savings of $42.9 \%$ related to energy integration (compared to a system without energy recovery) [26]. The data for the equipment for heating and cooling (Table $\mathrm{S}$ 4) and their energy demand were upscaled to match a continuous process design at a large scale [37]. For this, electricity input savings in large-scale production of $15 \%$ were considered [37]. The energy demand for the pervaporation pump was scaled up linearly without any economies of scale due to a lack of information on flow rates.

Based on the data from the pilot scale, the biobutanol concentration was determined to be $2.65 \mathrm{~g} / \mathrm{l}$. The pervaporation process was modelled accordingly. However, the pervaporation model showed that a minimal biobutanol concentration of $10 \mathrm{~g} / \mathrm{l}$ has to be achieved to reach a breakeven point in energy input and output [26]. Based on the productivity and concentration of biobutanol in the PBRs, a partial daily harvest has been calculated with a fixed volume of $30 \%$ of the total culture to maintain a stable biological system. The energy requirements for pervaporation were considered in the LCA model, assuming a yearly operation of 360 days and a daily full-time 24-h operation (Table S 5). Simultaneously to the harvesting process, a fresh medium with fertiliser was added to achieve constant cultivation conditions. Following the process simulations by Wagner et al. [26], in the LCA, the butanol-rich flow in the system is treated with a two-step pervaporation process and a final distillation column to purify the product. A process scheme can be depicted in Fig. 2. The pervaporation process is used to increase the biobutanol levels above the spontaneous butanol-water phase separation point. After this, it is possible to separate and recycle the aqueous phase back to the separation system and recover the biobutanol from the organic phase through distillation. Each pervaporation unit requires a heater, a condenser and a vacuum pump to reduce the outlet pressure. The vacuum pumps are defined to be outside the system boundaries of this study, as no data was 
Table 3 Description of the cultivation system

Cultivation system

Specific materials

Production and preparation steps providing less than $1 \mathrm{~m}^{3}$ of culture were neglected and considered lab work outside the system boundaries. The primary materials of the production system were taken into account without assembling, forming and construction processes. Whenever catalogue data were used on electric devices like the blower, $70 \%$ of the total mass was assumed to be stainless steel. The main materials used within the cultivation phase are listed in Table S 2

Energy Pump work and culture bubbling were applied, too. Optimal pumps were selected using the flow rates $\left(30 \mathrm{~m}^{3} / \mathrm{h}, 83\right.$ $\mathrm{m}^{3} / \mathrm{h}, 500 \mathrm{~m}^{3} / \mathrm{h}$ ) per reactor size given by Guerra, T. (personal communication, September 19, 2018) to ensure a culture speed of $0.5 \mathrm{~m} / \mathrm{s}$. No power for thermoregulation is considered since spray water cooling is assumed to be used during the summer period (no additional pumping, tap water). Energy consumption for 360 production days can be depicted in Table S 3. Sensors and controlling equipment, as well as connecting pipes between the different production steps, were neglected

Operational materials Values for operational materials like fertiliser, freshwater for cleaning purposes, thermoregulation or fresh culture supply were calculated based on information provided by Guerra, T. (personal communication, February 4, 2019). Like this, we considered $107 \mathrm{~g} \mathrm{~N} / \mathrm{kg}$ DM biomass as $\mathrm{NaNO}_{3}$ and $15 \mathrm{~g} \mathrm{P} / \mathrm{kg}$ DM biomass as $\mathrm{P}_{2} \mathrm{O}_{5}$. According to literature, $62.5 \%$ of nitrogen and $90 \%$ of phosphate can be recycled within a hydrothermal liquefaction (HTL) process [42], significantly reducing the nutrient demand from primary sources, which are either limited (phosphate rock) or linked to energy-demanding production processes (Haber-Bosch process)

$\mathrm{CO}_{2}$ supply Bioenergy systems are assumed to be carbon-neutral since the plants take the carbon stored in the biomass from the atmosphere. Consequently, the biomass has effectively removed carbon from the atmosphere (short-term perspective). Therefore, any thermochemical or biological conversion of biomass, which releases carbon dioxide into the atmosphere, does not contribute to any net additional greenhouse gases [43]. However, microalgae and cyanobacteria need to be supplied with higher $\mathrm{CO}_{2}$ concentrations than available in the atmosphere to achieve high productivities. $\mathrm{CO}_{2}$ sources providing such higher concentrations can be provided, e.g. by biogas plants. $\mathrm{CO}_{2}$ will be taken up during photosynthesis and assimilation by the algae. As it will be released while burning the biobutanol in a combustion engine, we did not include the process in the LCA. We did not consider any technical supply of $\mathrm{CO}_{2}$

Water for cleaning As it is assumed that the system is running continuously, only one cleaning per year occurs, flushing the tubes with twice the water volume of the reactors and a solution with chlorine $(7.0 \mathrm{~kg})$ and thiosulfate $(5.6 \mathrm{~kg})$

Water for process Recycling of the culture medium is assumed to reduce the freshwater consumption, totaling $433 \mathrm{~m}^{3}$, including the water demand for the cooling system per year caused by evaporation. As $90 \%$ of the culture broth harvested can be recycled and fed back to the PBR system, the total freshwater volume per year can be reduced to $83 \mathrm{~m}^{3}$

Biomass as co-product Daily harvesting of around 30\% of the culture was assumed. The yearly biobutanol production was considered to be about $2000 \mathrm{t}$ and $1080 \mathrm{t}$ of biomass as co-product. Differences in densities of biomass, biobutanol, and culture medium were not considered for technical configuration and processing

available. All aqueous streams are recycled to minimise the required fresh water and recover the entire residual butanol.

\section{Scenario Development}

Three different scenarios for the production of biobutanol were developed and analysed. The specifications for the three scenarios and their major input parameters are shown in Table 4. The first scenario "Upscale" is regarded as the baseline scenario for a 20 ha system on which the other scenarios were built. The specifications of the second and third scenarios remain the same while only the energy source was changed.

\section{HTL and Nutrient Recovery}

The scenario "Upscale + HTL" is based on the "Upscale" scenario, but supplemented by an HTL process, a further downstream step to valorise the biomass as well as to recycle nutrients (Fig. 3). Pre-studies showed that biomass valorisation should be included to improve the overall efficiency of the process, e.g. by recycling nutrients as well as increasing the energy output [45]. For this work, the HTL process has been considered as the most suitable technology to convert the residual algae biomass since HTL, in general, is appropriate for the conversion of wet feedstocks [42]. Besides, HTL delivers a liquid energy carrier, so-called bio-crude oil, which can be upgraded and used as fuel as well.

Most HTL published research has been performed using small-batch reactors, typically a few hundred millilitres in volume. On the other hand, the present LCA study comprises an upscaled HTL process operating $24 \mathrm{~h}$ a day, with a daily feed of about 15,000 L, which was designed according to Jones, Zhu, Anderson, Hallen \& Elliot [42] and Zhang et al. [46] and complemented by experimental data provided by Wagner et al. [26]. As a result, in the presented LCA, residual algal slurries with $20 \% \mathrm{DM}$ content were considered as processed and converted by a high temperature $\left(350^{\circ} \mathrm{C}\right)$ and pressure (210 bar) reaction into four streams (Boatman, 


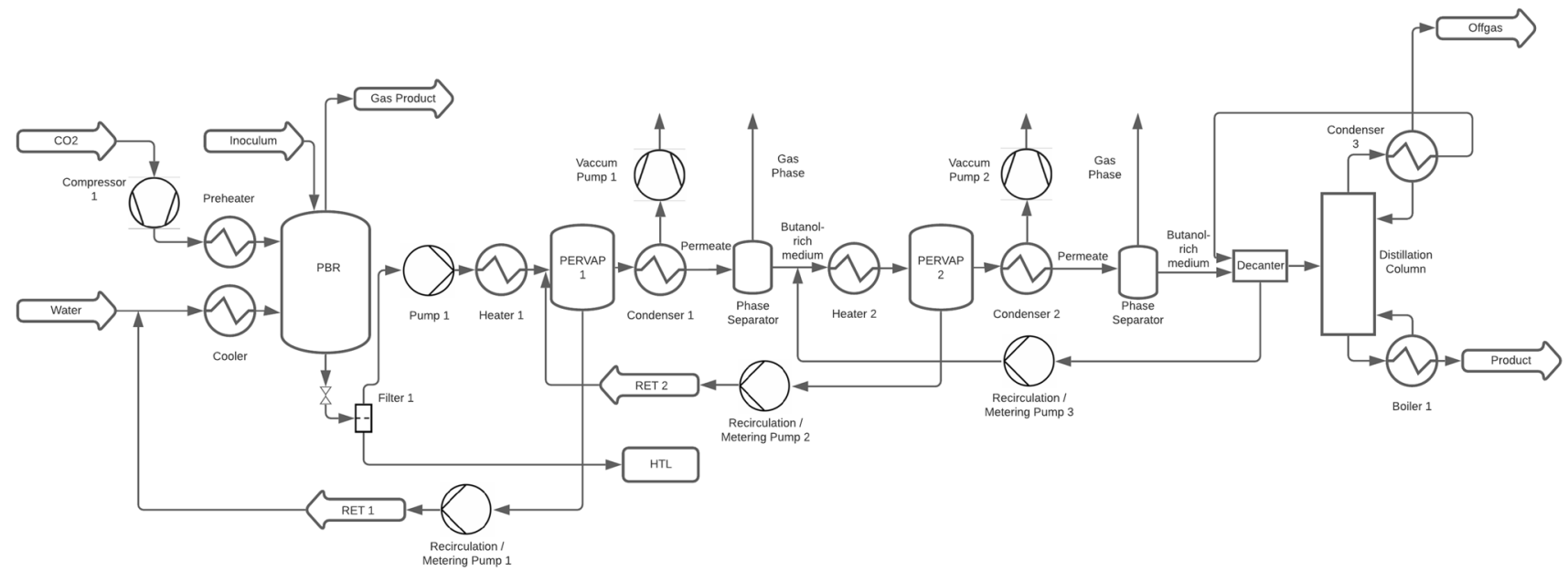

Fig. 2 Flow diagram of the biobutanol production process according to Wagner et al. (2019), modified

Table 4 Major input parameters for the scenarios "Upscale" and "Upscale + HTL"

\begin{tabular}{llc}
\hline Key parameters & Upscale & Upscale + HTL \\
\hline $\begin{array}{l}\text { Productivity [mg/L/day] } \\
\text { Biomass/biobutanol ratio }\end{array}$ & 600 & \\
$\begin{array}{l}\text { Electricity demand [kWh/kg biobu- } \\
\quad \text { tanol] }\end{array}$ & $0.35: 0.65$ & 156 \\
$\mathrm{CO}_{2}$ & Flow is not considered in the LCA due to the biogenic source \\
$\begin{array}{l}\text { Nitrogen fertiliser } \\
{[\mathrm{kg} / \mathrm{kg} \text { biobutanol }]}\end{array}$ & 0.35 & 0.13 \\
$\begin{array}{l}\text { Phosphorus fertiliser } \\
\text { [kg/kg biobutanol] }\end{array}$ & 0.04 & $(62.5 \%$ recycling $)$ \\
$\begin{array}{l}\text { By-product credit } \\
{[\mathrm{kWh} / \mathrm{kg} \text { biobutanol] }}\end{array}$ & n.a & 0.004 \\
Electricity mix (2012) & & $30 \%$ recycling) \\
\hline
\end{tabular}

$H T L$, hydrothermal liquefaction

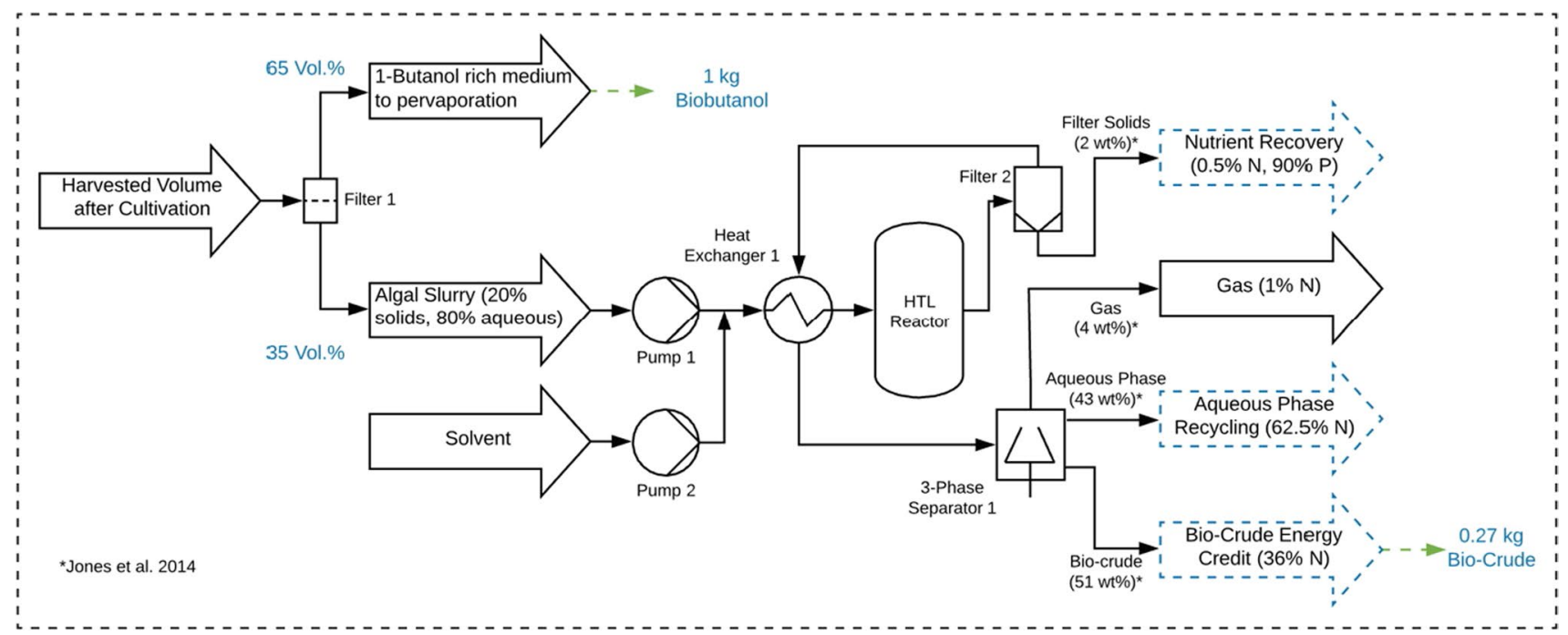

Fig. 3 Flow diagram of the HTL process as implemented in the LCA model (based on Jones et al. (2014) [42]) 
T., personal communication, January 7, 2019). A generic organic co-solvent (1,1 dimethyl cyclopentane was chosen as a reference) is included to support the separation of the bio-oil from the other products. The solvent flow rate was set to $10 \%$ of the total flow entering the HTL process (Boatman, T., personal communication, January 7, 2019). The process of solvent recycling itself was not considered to be within the system boundaries of this LCA study. However, a solvent recycling rate of $99.9 \%$ is applied as a credit, according to Liu et al. [37].

Figure 3 shows the HTL process as considered in the presented model, the product yields and the nutrient amount according to data from a case model [42]. This so-called "Aspen Design Case Model" was developed based on experimental results for Nannochloropsis and Chlorella from three other algae types from unpublished works that make this model applicable for fresh and saline water algae [42]. Table 5 shows elementary compositions and ash content of Synechocystis PCC6803 and the reference algae used in this study for HTL [47].

A list of equipment used in the HTL phase is given in Table S 6. For the full-scale model, all equipment inputs were dimensioned according to the upscaled flows that pass the system. After passing the HTL reactor, the solid phase is being removed from the product flow by a ceramic filter as a first step. Subsequently, a 3-phase separator is needed to isolate the other product phases [42]. According to the Aspen design case model [42], the HTL product contains $51 \mathrm{wt} . \%$ bio-crude (dry), $43 \mathrm{wt} . \%$ of the aqueous phase, four wt.\% of product gas and two wt.\% of solids, based on dry algae. Streams refer to the biomass flow as reported by Jones et al. [42]. Figure 3 shows the nitrogen balance in the product streams as estimated from experimental results based on Jones et al. [42]. In the present LCA, the nitrogen and phosphorus bound in the resulting solid and aqueous phases are internally recycled and used as a credit for the substitution of inputs [48] in the model, reducing the external nutrient demand during cultivation.

Table 5 Elementary composition and ash content of Synechocystis PCC6803

\begin{tabular}{lll}
\hline & $\begin{array}{l}\text { Synechocystis PCC6803 } \\
{[47]}\end{array}$ & $\begin{array}{l}\text { Aspen design } \\
\text { case model } \\
{[42]}\end{array}$ \\
\hline Component & $($ wt. $\%)$ & $($ wt. $\%)$ \\
C & 49.8 & 52 \\
$\mathrm{H}$ & 6.7 & 7.5 \\
$\mathrm{O}$ & 26.8 & 22 \\
$\mathrm{~N}$ & 12.5 & 4.8 \\
$\mathrm{~S}$ & 0.7 & 0.61 \\
$\mathrm{P}$ & 1.5 & 0.6 \\
Ash & 2.7 & 13 \\
\hline
\end{tabular}

Before re-using it for algae cultivation, the solid fraction from HTL requires a conversion step (such as acid digestion) to make the phosphorus bound bioavailable [42] However, any further processing of nutrients to enhance bioavailability and the separation of the solvent and biocrude were considered to be outside the system boundaries, as no data was available. For the HTL process, the energy inputs are contemplated (Table S 7). With every $\mathrm{kg}$ of biobutanol, $0.27 \mathrm{~kg}$ of bio-crude oil (HHV $39 \mathrm{MJ} /$ $\mathrm{kg}$ ) [49] are produced and considered in the LCA model as energy credit for biobutanol production. It is assumed that bio-crude oil is used to produce electricity with a conversion efficiency of $40 \%$ [50]. The produced gas is not recycled or used as its amount is negligible (4 wt.\%).

\section{Renewable Energy Supply}

The results of the pre-study LCA on data from a small-scale pilot plant operation showed that the electricity demand for algae cultivation and harvest has a major impact on the LCA results because of the environmental impacts of the nonrenewable sources-based electricity supply. Therefore, the standard European electricity mix has been changed to a renewable energy mix for the third scenario based on the conditions of the energy supply in Norway, where hydropower is dominating the electricity market with a share of $96.2 \%$ [51]. This electricity mix scenario was chosen to approximate the time after the energy transition, whereas there is no real intention to import electricity from Norway. As the biobutanol separation also requires energy in terms of heat, the heat supply was changed to renewable sources (biogas).

\section{Results and Discussion}

In the following sections, the LCA results for the three scenarios are shown and discussed comprising both, issues regarding the modelling approach and specific scenariorelated aspects.

\section{Modelling Aspects}

The underlying study describes a theoretical system mainly driven by assumptions on the biological system set up technically. As LCA considerations describe linear correlations, these assumptions have a significant influence on the results. In general, the level of uncertainty, mainly due to lacking data for technologies at low TRL and related to upscaling and modelling issues $[29,52]$ is a challenge that limits the 
comparability of the results for an emerging technology with an approved and mature technology [53].

Biobutanol production with microalgae and cyanobacteria is a process that is still in its infancy and significant productivity improvements can be expected in particular if novel biotechnology is applied. For different cyanobacteria mutants, biobutanol productivities of $15 \mathrm{mg} / \mathrm{L} / \mathrm{d}$ in 2012 [54] and $64 \mathrm{mg} / \mathrm{L} / \mathrm{d}$ in 2017 [55] are reported. However, the setting is not comparable due to another genetic engineering technique and differences in the production systems applied. In 2019, maximum biobutanol productivity with engineered cyanobacteria of $302 \mathrm{mg} / \mathrm{l} / \mathrm{day}$ was achieved [56]. The literature review shows the vast potential of increasing productivity through engineering progress within only a short time. This trend indicates the opportunity further to reduce the environmental impacts of algae biobutanol production. In this study, it is assumed that assume prospective bestcase biobutanol productivity of $600 \mathrm{mg} / \mathrm{L} / \mathrm{day}$, which was reported for a lab-scale system in 2018 [40]. The nutrient supply must be adjusted to reach high productivities. That is also true for the supply of $\mathrm{CO}_{2}$, which is needed as additional $\mathrm{CO}_{2}$-fertilisation. These $\mathrm{CO}_{2}$ inputs were neglected for this study. However, appropriate $\mathrm{CO}_{2}$ accounting methods should be further developed for $\mathrm{CO}_{2}$-dependent biofuel systems. Especially in the discussion of synthetic fuels (i.e. e-fuels), such a framework will be required.

\section{Process Contribution}

The following paragraphs describe the LCA results of the three scenarios identifying the main hotspots and bottlenecks of biobutanol production.

\section{Scenarios}

The obtained results for all scenarios in the underlying study are displayed in the same way, referring to the production of $1 \mathrm{~kg}$ of biobutanol. Especially electricity and operational materials, e.g. fertilisers and the embedded burdens of the materials used, contribute to the impact assessment results. Processes contributing to less than $2 \%$ to each impact category were summarised as "others".

\section{Scenario Upscale}

The baseline scenario "Upscale" comprises operational conditions and processes that were experimentally tested and verified at a small scale only but upscaled for this study to fulfil industrial requirements. Figure 4 shows that the highest share within climate change $\left(38.9 \mathrm{~kg} \mathrm{CO}_{2}\right.$ eq), freshwater eutrophication $(0.02 \mathrm{~kg} \mathrm{P} \mathrm{eq})$ and particulate matter formation (0.01 PM2.5 eq) is resulting from the energy consumption $(92 \%, 90 \%$ and $74 \%$, respectively). As expected, the land use category and the mineral depletion category are mainly related to the infrastructure like the reactor system itself (53\% and 59\%, respectively). However, the land use category, expressed as kg soil organic carbon (SOC), is a soil quality indicator significant for assessing the impacts on fertile land use (agriculture and forestry systems). Only the "occupation of industrial area" without any land transforming processes within the infrastructure inventory is considered, as it is referred to as an industrial-scale production [35].

The SOC indicator provides directly relevant information for assessing a system's net contribution to the Global Warming Potential (GWP) through the effect on the soil carbon pool [57]. However, the soil mechanisms regarding carbon capture and release related to land use change (LUC) are complicated and different LUC measures might be more adequate as this impact category was a crucial part of recent debates on the sustainability of biofuels $[6,7]$. Operational materials dominate the impact category of water depletion (52\%). Here, freshwater inputs for cooling as well as for medium preparation are considered. Besides, the main contributors' electricity, infrastructure and fertiliser inputs represent a significant share in the overall LCA impacts.

\section{Scenario Upscale $+H T L$}

Compared to the baseline scenario "Upscale", the LCA results for the scenario "Upscale + HTL" improved for all selected impact categories in different proportions (Fig. 5). A reduction from 38.99 to $37.72 \mathrm{~kg} \mathrm{CO}_{2}$ eq can be observed for climate change. The absolute share of nutrients decreased from 4.7 (upscale) to $1.7 \mathrm{~kg} \mathrm{CO}_{2}$ eq. Since a credit along the production process for the bio-crude oil produced is applied, the definite value on $\mathrm{CO}_{2}$ eq for the electricity consumption is reduced from 35.9 (upscale) to $35.8 \mathrm{~kg} \mathrm{CO}_{2}$ eq. However, this saving is counterbalanced by the energyintense HTL process itself. The main pattern of contributors to the impacts remains the same. With a reduced contribution of fertiliser, the impact in mineral resource depletion from resources for nutrient production decreases from 16.9 to $4.6 \%$ (related to nutrient production). Although more energy is needed absolutely, the savings concerning nutrients improve the overall results. Thus, the application of HTL proved to be beneficial in environmental terms.

\section{Scenario Upscale $+H T L+N O$}

In the third scenario, the electricity supply was changed to the Norwegian mix while the heat supply was switched to biogas from the waste stream in a Norwegian setting. In this scenario, the climate change impact decreased to an absolute value of $3.08 \mathrm{~kg} \mathrm{CO}_{2}$ eq. Besides, the infrastructure implications became more evident in most impact categories 


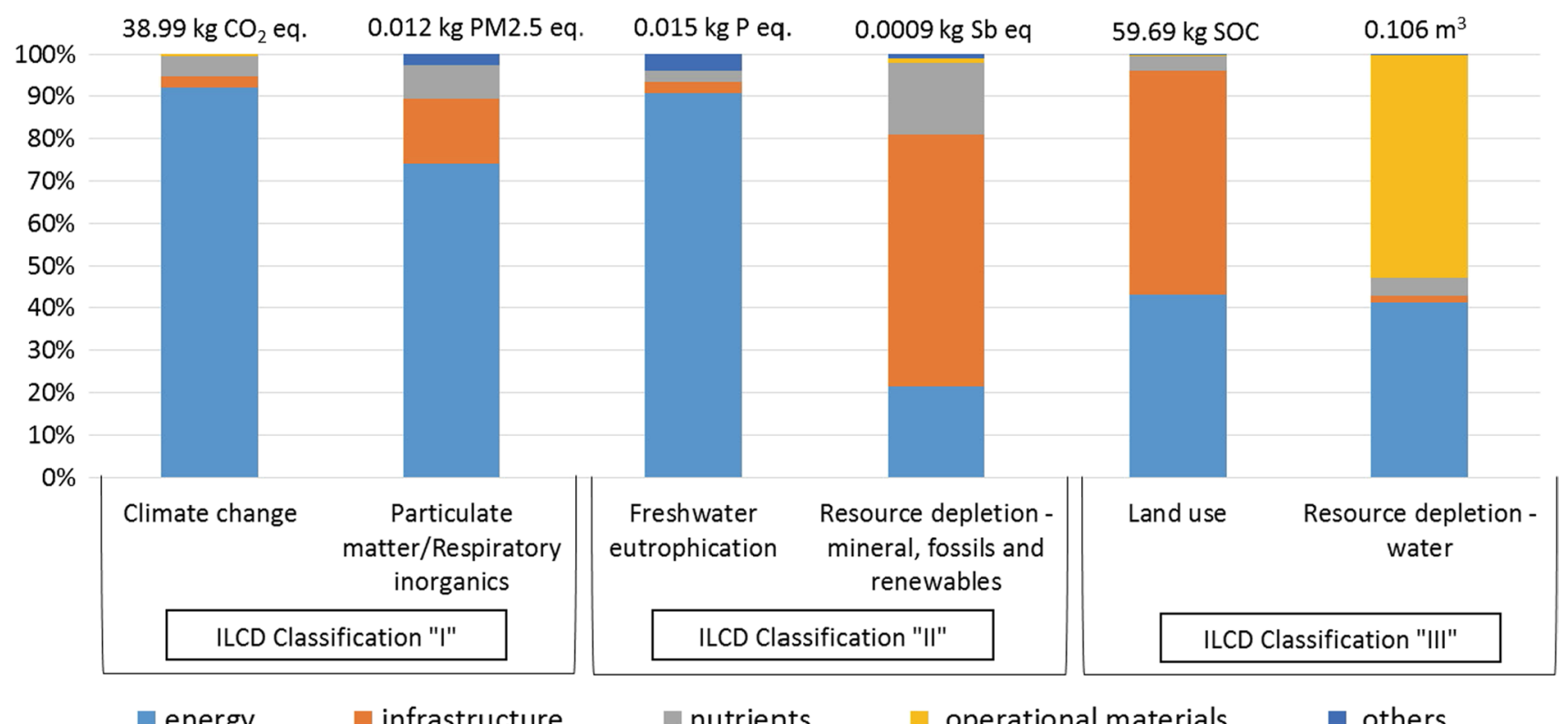

Fig. 4 LCA results for biobutanol production with Synechocystis PCC6803 in UHT-PBR (scenario upscale). Contribution of clustered impacts to relevant impact categories recommended by the ILCD handbook

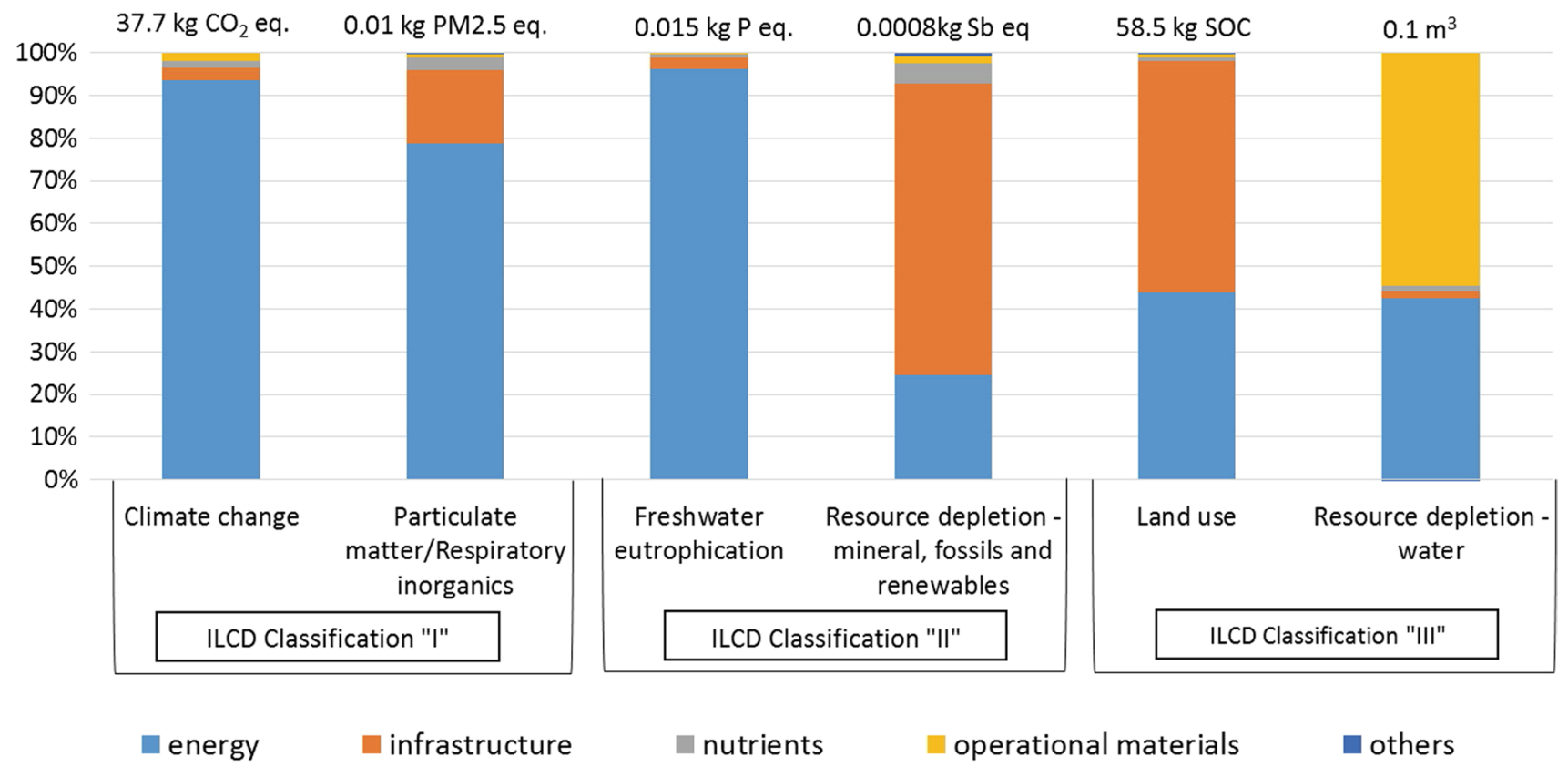

Fig. 5 LCA results for biobutanol production with Synechocystis PCC6803 in UHT-PBR (scenario upscale + HTL). Contribution of clustered impacts to relevant impact categories recommended by the ILCD handbook

and dominated the results while the pattern of contribution changed. For most impact categories, the results improved. Nevertheless, the value of water depletion increased significantly (Fig. 6). The absolute values of depleted water increased from 0.11 to $0.23 \mathrm{~m}^{3}$ per $\mathrm{kg}$ of biobutanol. However, the ILCD methodology of accounting for water used in hydropower turbines is considered misleading. The characterisation factor for "Water, turbine use, unspecified natural origin, NO" is $5.35 \times 10^{-4} \mathrm{~m}^{3}$ water eq $/ \mathrm{m}^{3}$, which drives the water depletion impact category in the foreground system to about $48 \%$. The background system, which was not affected by the exchange of the electricity mix, remained the same 
in terms of absolute values. There is a comprehensive discussion in the literature about the methods' reliability and appropriate dedication of water flows to impact categories, e.g. how the water used in turbines is considered. Bakken et al. [58] suggest setting turbine water to zero in the assessment since there is no water consumption within the spatial boundaries.

\section{Comparison of Scenarios and Fossil Reference}

The results of comparing the normalised results of the different scenarios with the fossil reference are shown in Fig. 7. The "zero lines" refers to the reference system $(1 \mathrm{~kg}$ of 1-butanol from hydroformylation), to which the results were normalised. The LCA results of the third scenario, "Upscale + HTL + NO", indicate that the energy transition will significantly impact the environmental competitiveness of biobutanol produced with Synechocystis PCC6803 compared to the fossil reference. This is true for climate change (upscale + HTL + NO: $3.1 \mathrm{~kg} \mathrm{CO}$ eq $/ \mathrm{kg}$ biobutanol versus fossil reference: $2.45 \mathrm{~kg} \mathrm{CO}_{2}$ eq. $/ \mathrm{kg}$ 1-butanol) and freshwater eutrophication (upscale + HTL + NO: $0.0009 \mathrm{~kg}$ $\mathrm{P}$ eq./kg biobutanol versus $0.0008 \mathrm{~kg} \mathrm{P}$ eq./kg 1-butanol), which shows a positive perspective for further optimizations of biobutanol production by cyanobacteria.

\section{Discussion}

This paper investigates the environmental sustainability of the production of biofuels with an innovative process applying genetically engineered microalgae already at an early stage of technology development. The objective of this work was to test the hypothesis that engineered microorganisms can outperform natural strains and contribute to reducing greenhouse gas emissions in the transportation sector. In this context, LCA is applied as an established tool for environmental sustainability assessment. Combining LCA with an exergetic analysis provides a more holistic approach to sustainability features. The exergy concept was applied because exergy quantifies the ability to cause change and is not conserved, unlike energy, which exposes the inefficient processes [59]. During the exergy analysis, the exergy consumption and the exergy efficiency of the different subprocesses (process level) and the entire foreground production system (gate-to-gate) were determined. Furthermore, a cradle-to-gate life cycle analysis (LCA) has been performed because of the increasing awareness of the possible impact of the whole chain of products, processes and services.

The other objective was to demonstrate the importance of assessing the environmental impacts at an early stage of technology development since biologists and microorganism process engineers make the most significant design decisions at the lab and pilot scale. However, current life cycle-based LCA tools and databases are not adapted to these needs. Moreover, microalgae and cyanobacteria cultivation and the linked upstream and downstream technologies are still under development and are characterised by a low TRL level. Thus, only a few data from lab- and pilot-scale experiments are available for conducting an LCA. Therefore, LCA simplification strategies for prospective and upscaled

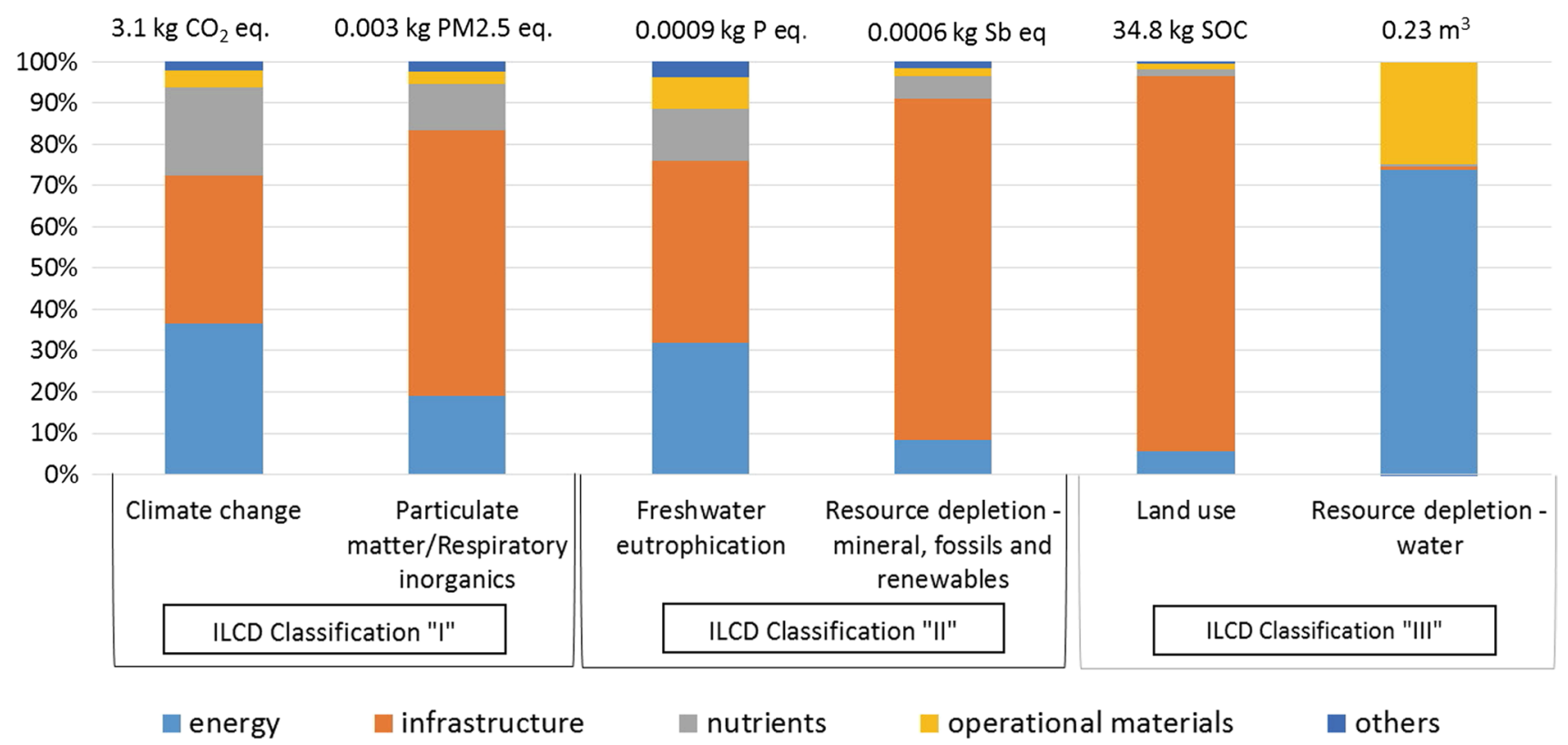

Fig. 6 LCA results for biobutanol production with Synechocystis PCC6803 in UHT-PBR (scenario upscale + HTL + NO). Contribution of clustered impacts to relevant impact categories recommended by the ILCD handbook 


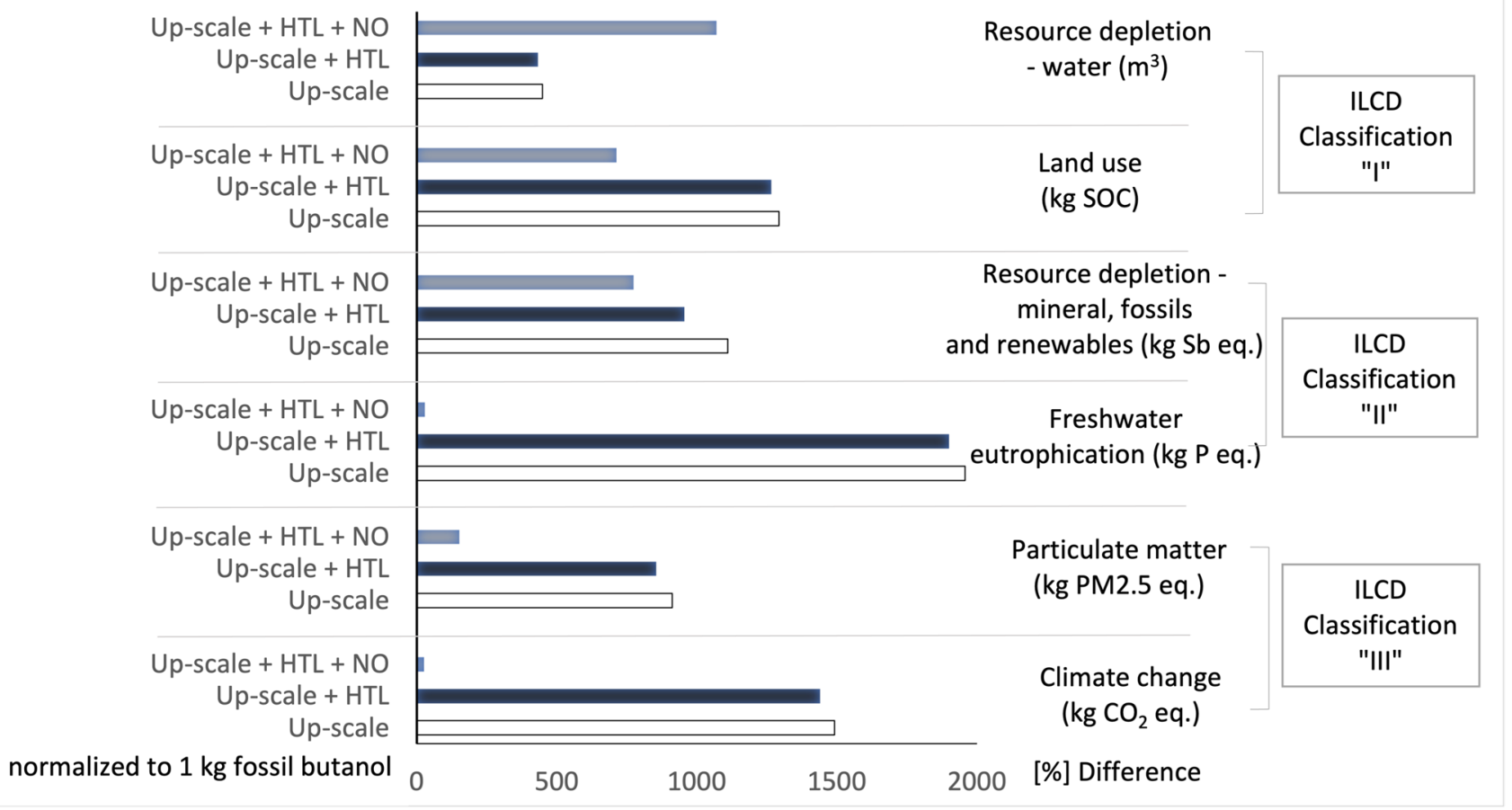

Fig. 7 Comparison of absolute LCA results for biobutanol production with Synechocystis PCC6803 in UHT-PBR by scenario and fossil reference, normalised to the fossil reference system

assessments are needed. Dealing with the uncertainties of modelling upscaled production systems and deriving data for such large-scale systems is a great challenge and a crucial task, as assumptions made in this process will significantly impact the environmental impacts of algal biomass and biofuel production. This task must be carried out with special care and responsibility because recommendations for the political frame conditions and the bio-technical process design will be derived.

The results of this work revealed the importance of LCA for the environmental assessment of new technologies at an early stage of development to know how to improve the technology from the biological and technical point of view. The first challenge was to build up a confidential and trusting working relationship with technology developers and pilotscale plant operators to convince project partners to collect and share specific LCA relevant data. Technology developers, engineers and plant operators often underestimate and insufficiently consider the time and effort required to prepare and provide LCA input data in their work plans and budgets. They are not always aware of providing sophisticated, reflective, detailed and accurate data for the LCA (e.g. input substrates, chemicals and energy). Thus, as given, data is often not suitable (i.e. equipment in place was used as-is and not optimised at all) to be applied as such in the LCA. The given data are not always applicable to prepare proxies.
The second challenge was reducing inaccuracy, increasing the reliability of data used in the LCA and closing the data gaps apparent after the experimental data collection. It proved to be very difficult to apply the LCA as a sustainability assessment tool. A combination of exergetic analysis and LCA might be a more holistic approach and benefit the sustainability features and long-term viability of biofuel and bioproducts production systems (biorefineries). Aghbashlo et al. [60] showed the exergy efficiency of a lignocellulosic biorefinery annexed to a sugar mill for simultaneous lactic acid and electricity production using sugarcane bagasse and brown leaves as feedstock by $44.7 \%$. The exergy concept can show the bottlenecks in thermodynamic inefficiency, cost loss and environmental impact as exergy is not conserved [59]. By applying advanced sustainability assessment methods, an in-depth investigation of the possible effects of the complete product chain, processes and services, can be carried out. Recent publications on exergetic analyses, e.g. Fallahi et al. [61] showed the exergy efficiency of producing a biobased platform chemical, indicating the need to emphasise interactions among subsystems of processes and their potential improvements. However, Soltanian et al. [62] states that most published work (on lignocellulosic biofuelbiorefineries) focuses on quantifying thermodynamic imperfections and determining exergetic efficiencies of the simulation. Therefore, exergo-economic and exergo-environmental 
approaches can provide more significant benefit and should focus on future biofuel production investigations.

LCA on technologies at relatively low TRL is complex and challenging due to lacking data and information. Although empirical data is preferably used, data from literature and inventory data (e.g. Gabi or Ecoinvent that is not always up-to-date) need to be applied to complete the LCA data. Thus, modelling took place with a mixture of different data types. For the prospective evaluation of the future technology potential of engineered microorganisms, an interdisciplinary team is needed to agree on the scenario design and the assumptions for the upscaling process. Therefore, we developed a shared understanding and vocabulary was developed to find solutions on how to do upscaling. It has to be noted that prospective LCA can only be made on the current state of the art and observed learning curves for technologies and processes. The limit of this work is that upscaling was performed mainly with a linear approach regarding process design, materials, and equipment, as a proxy for the modular process design of microorganism cultivation in photobioreactors. This limit could be overcome by applying nonlinear upscaling, applying engineering software such as SuperProDesigners or Aspen.

The LCA scenario results show that the primary hotspot of biobutanol production with genetically engineered cyanobacteria is the electricity demand. The energy transition helps the process to become more environmentally friendly. As the system was based on theoretical estimations, no specific recommendations for process improvements can be given. Nevertheless, we consider biobutanol production with cyanobacteria Synechocystis PCC6803 as innovative technology, which could be ecologically competitive to the fossil reference if the political conditions of a circular bioeconomy and a successful energy transition in Europe can be achieved. Therefore, it seems promising to continue and strengthen $R \& D$ on engineered production processes to supply sustainable biofuels as an alternative for bioelectric transportation, particularly air transportation. Without a successful energy transition, it will be challenging to achieve sustainable biobutanol production with microalgae relying on the state of the art technologies.

Moreover, there is an urgent need to significantly reduce the electricity demand for algae cultivation and product harvest. However, the modular structure of the biobutanol production process based on single photobioreactors limits the possibilities to achieve significant improvements in environmental impacts by economies of scale only. The LCA results indicate that integrating the HTL process to recycle the nutrients can reduce the environmental impacts. Still, large-scale implementation of the HTL process needs to be approved to ensure that no disturbances or disadvantages in the cultivation process occur due to nutrient recycling. Combining different production steps with relatively low TRL is a challenge for upscaling due to the lack of knowledge and data. Therefore, this work is an essential first step to give orientation knowledge on the environmental impacts of future biobutanol production with algae.

The third challenge of the LCA work is the responsibility of dissemination and communication of the LCA results. For technology developers, it is essential to identify hotspots and leverage points to improve process design based on LCA insights at large-scale production and societally possible scenarios. Beyond that, LCA results have an impact on research and development targets and funds. Therefore, biologists and process engineers strongly motivate LCA experts to work with the best available data to produce "good" results required from society to develop further and implement engineered microorganisms [3, 63]. The comparison with other studies addressing this technology, e.g. Nilsson et al. [64], is challenging because these are theoretical studies based only on literature assumptions to construct a hypothetical production scheme with different reactors and conditions. Nevertheless, it can be noted that one of the productivities used by Nilsson et al. [64] is in the same range of the biobutanol productivity presented in this work $(600 \mathrm{mg} / \mathrm{L} /$ day $)$, but significantly higher in comparison with previous literature.

\section{Conclusions and Future Directions}

The responsibility of LCA experts is relatively high as they are considered environmental judges on new technologies by measuring and evaluating the perspectives of replacing an established technology or process with a new one. However, LCA researchers are experts in their field and do not always have the sufficient process engineering knowledge required for sophisticated upscaling and designing large-scale plants. Besides, there is no agreed procedure for upscaling approaches of new technologies at low TRL level, the increase of robustness of assumptions, or the application of learning curves. Moreover, no common understanding of dealing with the high level of uncertainty associated with upscaling in LCA exists, except to provide the utmost transparency of modelling and assumptions made. Thus, assessing the environmental sustainability of biobutanol production with genetically engineered microorganisms in photobioreactors at an early stage of technology development is challenging. This is all the more true as there is no data basis for this assessment.

Therefore, this study is considered the first LCA of biobutanol production through genetically modified cyanobacteria with lab- and pilot-scale data. In this work, the highest productivity analysed in the lab was used for the LCA. Although critics could argue that this is a somewhat optimistic evaluation, it is justifiable to identify which conditions optimise 
the environmental impacts. The results show that biofuels produced with genetically engineered microorganisms are a promising option for future sustainable transportation, mainly where vehicles with renewable electricity or hydrogen are not feasible. In future studies, the relevant parameters, such as upscaled system configuration and management of input and output flows, need to be addressed carefully and further investigated by applying engineering software such as SuperProDesigners or Aspen. In addition, climatic conditions and previous land use of production sites and circular and biogenic sources of $\mathrm{CO}_{2}$, fertiliser and water (e.g. biogas plants) must also be considered since this could further improve the environmental sustainability of biobutanol production.

Supplementary Information The online version contains supplementary material available at https://doi.org/10.1007/s12155-021-10323-y.

Acknowledgements The authors would like to thank the PHOTOFUEL project partners for providing original data from the lab and pilot scale and discussing upscaled data to assess the environmental impact of biobutanol production with engineered cyanobacteria.

Funding This work was supported by the European Union's Horizon 2020 research and innovation program under grant agreement 640720.

Data Availability All data generated or analysed during this study are included in this published article [and its supplementary information files].

\section{Declarations}

Conflict of interest The authors declare no competing interests.

Open Access This article is licensed under a Creative Commons Attribution 4.0 International License, which permits use, sharing, adaptation, distribution and reproduction in any medium or format, as long as you give appropriate credit to the original author(s) and the source, provide a link to the Creative Commons licence, and indicate if changes were made. The images or other third party material in this article are included in the article's Creative Commons licence, unless indicated otherwise in a credit line to the material. If material is not included in the article's Creative Commons licence and your intended use is not permitted by statutory regulation or exceeds the permitted use, you will need to obtain permission directly from the copyright holder. To view a copy of this licence, visit http://creativecommons.org/licenses/by/4.0/.

\section{References}

1. European Commission. New study investigates properties of bio kerosene fuel blends 2019. https://ec.europa.eu/energy/en/news/ new-study-investigates-properties-bio-kerosene-fuel-blends. Accessed 5 Dec 2019

2. Henley WJ, Litaker RW, Novoveská L, Duke CS, Quemada HD, Sayre RT (2013) Initial risk assessment of genetically modified (GM) microalgae for commodity-scale biofuel cultivation. Algal Res 2:66-77. https://doi.org/10.1016/j.algal.2012.11.001
3. Varela Villarreal J, Burgués C, Rösch C (2020) Acceptability of genetically engineered algae biofuels in Europe: opinions of experts and stakeholders. Biotechnol Biofuels 13:92. https://doi. org/10.1186/s13068-020-01730-y

4. Ferreira da Silva A, Brazinha C, Costa L, Caetano NS (2020) Techno-economic assessment of a Synechocystis based biorefinery through process optimization. Energy Reports 6:509-14. https://doi.org/10.1016/j.egyr.2019.09.016

5. Benson D, Kerry K, Malin G (2014) Algal biofuels: impact significance and implications for EU multi-level governance. J Clean Prod 72:4-13. https://doi.org/10.1016/j.jclepro.2014.02.060

6. European Commission (2019) Regulations commission delegated regulation (EU) 2019/807. https://eur-lex.europa.eu/legal-conte nt/EN/TXT/PDF/?uri=CELEX:32019R0807. Accessed 13 Apr 2020.

7. Parliament E (2018) Directive (EU) 2018/2001 of the European Parliament and of the Council of 11 December 2018 on the promotion of the use of energy from renewable sources. Off J Eur Union 128:82-209

8. Gaber K, Rösch C, Biondi N (2021) Life cycle assessment of total fatty acid (TFA) production from microalgae nannochloropsis oceanica at different sites and under different sustainability scenarios. Bioenerg Res. https://doi.org/10.1007/s12155-021-10279-z

9. Wang Y, Ho SH, Yen HW, Nagarajan D, Ren NQ, Li S et al (2017) Current advances on fermentative biobutanol production using third generation feedstock. Biotechnol Adv 35:1049-1059. https:// doi.org/10.1016/j.biotechadv.2017.06.001.

10. Harish BS, Mekala JR, Babu UK (2015) Bioengineering strategies on catalysis for the effective production of renewable and sustainable energy. Renew Sustain Energy Rev 51:533-547. https://doi. org/10.1016/j.rser.2015.06.030

11. Lehr F, Morweiser M, Rosello Sastre R, Kruse O, Posten C (2012) Process development for hydrogen production with Chlamydomonas reinhardtii based on growth and product formation kinetics. J Biotechnol 162:89-96. https://doi.org/10.1016/j.jbiot ec.2012.06.002

12. Dutta S, Neto F, Coelho MC (2016) Microalgae biofuels: a comparative study on techno-economic analysis \& life-cycle assessment. Algal Res 20:44-52. https://doi.org/10.1016/j.algal.2016. 09.018

13. Rawat I, Ranjith Kumar R, Mutanda T, Bux F (2013) Biodiesel from microalgae: a critical evaluation from laboratory to large scale production. Appl Energy 103:444-467. https://doi.org/10. 1016/j.apenergy.2012.10.004

14. Rösch C, Roßmann M, Weickert S (2019) Microalgae for integrated food and fuel production. GCB Bioenergy 11:326-334. https://doi.org/10.1111/gcbb.12579

15. Parmar A, Singh NK, Pandey A, Gnansounou E, Madamwar D (2011) Cyanobacteria and microalgae: a positive prospect for biofuels. Bioresour Technol 102:10163-10172. https://doi.org/ 10.1016/j.biortech.2011.08.030

16. Nozzi NE, Oliver JWK, Atsumi S (2013) Cyanobacteria as a platform for biofuel production. Front Bioeng Biotechnol 1:1-6. https://doi.org/10.3389/fbioe.2013.00007

17. Miao R, Xufeng L, Lindberg P, Lindblad P (2017) Report on designed strains and optimized processes for production of short chain-length alcohols reaching at least TRL4. Deliverable D2.3. Photofuel Project. http://www.photofuel.eu/uploads/files/photo fuel-d2.3_butanol_biocatalyst_development.pdf

18. Bippes M (2017) Fuel matrix definition. Deliverable D5.1. Photofuel Project. https://www.photofuel.eu/uploads/files/photofueld5.1_fuel_matrix.pdf

19. Bevan E (2011) Algae to butanol : the design, construction, and implementation of an automated sugar-to-fuel process. Chemical Engineering Undergraduate Honors Theses 19. http://scholarwor ks.uark.edu/cheguht/19 
20. Shapovalov OI, Ashkinazi LA (2008) Biobutanol: biofuel of second generation. Russ J Appl Chem 81:2232-2236. https://doi.org/ $10.1134 /$ S 1070427208120379

21. Ketzer F, Skarka J, Rösch C (2018) Critical review of microalgae LCA studies for bioenergy production. Bioenergy Res 11:95-105. https://doi.org/10.1007/s12155-017-9880-1

22. Carmona-Garcia E, Mann-Valencia PA, Solarte-Toro JC, Moustakas K, Cardona-Alzate CA (2021) Comparison of acetonebutanol-ethanol fermentation and ethanol catalytic upgrading as pathways for butanol production: a techno-economic and environmental assessment. Biofuel Res J 8:1384-99. https://doi.org/10. 18331/BRJ2021.8.2.4

23. Veza I, Muhamad Said MF, Latiff ZA (2021) Recent advances in butanol production by acetone-butanol-ethanol (ABE) fermentation. Biomass Bioenerg 144:105919. https://doi.org/10.1016/j. biombioe.2020.105919

24. Amiri H (2020) Recent innovations for reviving the ABE fermentation for production of butanol as a drop-in liquid biofuel. Biofuel Res J 7:1256-66. https://doi.org/10.18331/BRJ2020.7.4.4

25. Kazemi Shariat PH, Dehhaghi M, Kinder JE, Ezeji TC (2019) A review on green liquid fuels for the transportation sector: a prospect of microbial solutions to climate change. Biofuel Research Journal 6(3):995-1024. https://doi.org/10.18331/brj20 19.6.3.2

26. Wagner JL, Lee-Lane D, Monaghan M, Sharifzadeh M, Hellgardt K (2019) Recovery of excreted n-butanol from genetically engineered cyanobacteria cultures: process modelling to quantify energy and economic costs of different separation technologies. Algal Res 37:92-102. https://doi.org/10.1016/j.algal.2018.11.008

27. Tursi A (2019) A review on biomass: importance, chemistry, classification, and conversion. Biofuel Res J 6:962-79. https://doi.org/ 10.18331/BRJ2019.6.2.3

28. García V, Päkkilä J, Ojamo H, Muurinen E, Keiski RL (2011) Challenges in biobutanol production: how to improve the efficiency? Renew Sustain Energy Rev 15:964-980. https://doi.org/ 10.1016/j.rser.2010.11.008

29. Chiaramonti D, Maniatis K, Tredici MR, Verdelho V, Yan J (2015) Life cycle assessment of algae biofuels: needs and challenges. Appl Energy 154:1049-1051. https://doi.org/10.1016/j.apenergy. 2015.06.006

30. de Jong S, Hoefnagels R, Wetterlund E, Pettersson K, Faaij A, Junginger M (2017) Cost optimization of biofuel production - the impact of scale, integration, transport and supply chain configurations. Appl Energy 195:1055-1070. https://doi.org/10.1016/j. apenergy.2017.03.109

31. van den Wall Bake JD, Junginger M, Faaij A, Poot T, Walter A (2009) Explaining the experience curve: cost reductions of Brazilian ethanol from sugarcane. Biomass Bioenerg 33:644-658. https://doi.org/10.1016/j.biombioe.2008.10.006

32. Bahadar A, Bilal KM (2013) Progress in energy from microalgae: a review. Renew Sustain Energy Rev 27:128-148. https://doi.org/ 10.1016/j.rser.2013.06.029

33. Wernet G, Bauer C, Steubing B, Reinhard J, Moreno-Ruiz E, Weidema B (2016) The ecoinvent database version 3 (part I): overview and methodology. Int J Life Cycle Assess 21:1218-1230. https://doi.org/10.1007/s11367-016-1087-8

34. Tillman A-M, Ekvall T, Baumann H, Rydberg T (1994) Choice of system boundaries in life cycle assessment. J Clean Prod 2:21-29. https://doi.org/10.1016/0959-6526(94)90021-3

35. JRC European Commission (2011) ILCD Handbook: recommendations for Life cycle Impact assessment in the european context. Publications Office of the European Union, Ispra (2011), 10.2788/33030. Available in: http://eplca.jrc.ec.europa.eu/uploa ds/ILCD-Recommendation-of-methods-for-LCIA-def.pdf
36. Cucurachi S, Van Der Giesen C, Guinée J (2018) Ex-ante LCA of emerging technologies. Procedia CIRP 69:463-468. https://doi. org/10.1016/j.procir.2017.11.005

37. Liu X, Saydah B, Eranki P, Colosi LM, Greg Mitchell B, Rhodes J et al (2013) Pilot-scale data provide enhanced estimates of the life cycle energy and emissions profile of algae biofuels produced via hydrothermal liquefaction. Bioresour Technol 148:163-171. https://doi.org/10.1016/j.biortech.2013.08.112

38. Zhang J, Zhang Y, Luo Z (2014) Hydrothermal liquefaction of Chlorella pyrenoidosa in ethanol-water for bio-crude production. Energy Procedia 61:1961-1964. https://doi.org/10.1016/j.egypro. 2014.12.052

39. Lauersen K, Kruse O (2017) Comparison of various biocatalytic strains and recommendation which strain should be collaboratively optimised - Milestone 2. Deliverable D2.4. Photofuel Project. hhttp://www.photofuel.eu/uploads/files/photofuel-d2.4_miles tone_strain_selection.pdf

40. Boatman T, Zemichael F, Wang X, Harun I, Vachiraroj N, Hellgardt K (2021) WP3 Activities and Outcomes. Photofuel Project. Unpublished Report.

41. Cooney MJ, Young G, Pate R (2011) Bio-oil from photosynthetic microalgae: case study. Bioresour Technol 102:166-177. https:// doi.org/10.1016/j.biortech.2010.06.134

42. Jones S, Zhu Y, Anderson D, Hallen RT, Elliott DC (2014) Process design and economics for the conversion of algal biomass to hydrocarbons: whole algae hydrothermal liquefaction and upgrading (No. PNNL-23227). Pacific Northwest National Lab.(PNNL), Richland, WA (United States). https://doi.org/10.2172/1126336

43. Thornley P, Adams P (2018) Policy lessons: the role of policy regimes in maximising GHG savings in bioenergy systems. Greenhouse Gas Balances of Bioenergy Systems 245-260. https:// doi.org/10.1016/B978-0-08-101036-5.00018-5

44. European Environment Agency (2004) EN19 Efficiency of conventional thermal electricity production. https://www.eea.europa. eu/data-and-maps/indicators/en19-efficiency-of-conventionalthermal. Accessed 13 Jan 2017.

45. Rösch C, Varela VJ (2021) Perception of EU citizens on engineered biocatalytic solar fuels. Renew Sustain Energy Rev 149:113. https://doi.org/10.1016/j.rser.2021.111366

46. Zhang B, Wu J, Deng Z, Yang C, Cui C, Ding Y (2017) A comparison of energy consumption in hydrothermal liquefaction and pyrolysis of microalgae. Trends in Renewable Energy 3:76-85. https://doi.org/10.17737/tre.2017.3.1.0013.

47. Kim HW, Vannela R, Zhou C, Harto C, Rittmann BE (2010) Photoautotrophic nutrient utilization and limitation during semicontinuous growth of Synechocystis sp. PCC6803. Biotechnol Bioeng 106:553-63. https://doi.org/10.1002/bit.22724

48. European Commission - Joint Research Centre - Institute for Environment and Sustainability: International Reference Life Cycle Data System (ILCD) Handbook - General guide for Life Cycle Assessment - Provisions and Action Steps. First editionMarch 2010. EUR 24378 EN. Luxembourg. Publications Office of the European Union; 2010. https://doi.org/10.2788/94987

49. Fessehaye Z, Boatman T, Hellgardt K (2018) Identification of optimal strategies for waste utilisation and recycle. Deliverable D3.6. Photofuel Project. http://www.photofuel.eu/uploads/files/ photofuel-d3.6_optimal_strategies_for_waste_utilisation_and_ recycle.pdf

50. European Environment Agency (2004) EN19 Efficiency of conventional thermal electricity production. http://www.eea.europa. eu/data-and-maps/indicators/en19-efficiency-of-conventionalthermal. Accessed 13 Jan 2017.

51. Itten R, Frischknecht R, Stucki M, Scherrer P, Psi I. (2012) Life cycle inventories of electricity mixes and grid. treeze Ltd., Uster, Switzerland. http://www.lc-inventories.ch 
52. Huijbregts MAJ (1998) Application of uncertainty and variability in LCA. Part I: a general framework for the analysis of uncertainty and variability in life cycle assessment. Int J Life Cycle Assess 3:273-80. https://doi.org/10.1007/BF02979835

53. Seidel C (2016) The application of life cycle assessment to public policy development. Int J Life Cycle Assess 21:337-348. https:// doi.org/10.1007/s11367-015-1024-2

54. Lan EI, Liao JC (2012) ATP drives direct photosynthetic production of 1-butanol in cyanobacteria. Proc Natl Acad Sci 109:60186023. https://doi.org/10.1073/pnas.1200074109

55. Miao R, Xufeng L, Lindblad P, Lindberg P (2017) Engineering isobutanol and 1-butanol synthesis pathways into the cyanobacterium Synechocystis PCC 6803. Photofuel Project. Unpublished Work

56. Liu X, Miao R, Lindberg P, Lindblad P (2019) Modular engineering for efficient photosynthetic biosynthesis of 1-butanol from $\mathrm{CO}$ 2 in cyanobacteria. Energy Environ Sci. https://doi.org/10.1039/ c9ee01214a

57. Brandão M, Milài Canals L, Clift R (2011) Soil organic carbon changes in the cultivation of energy crops: implications for GHG balances and soil quality for use in LCA. Biomass and Bioenergy 35:2323-36. https://doi.org/10.1016/j.biombioe.2009.10.019

58. Bakken TH, Modahl IS, Engeland K, Raadal HL, Arnøy S (2016) The life-cycle water footprint of two hydropower projects in Norway. J Clean Prod 113:241-250. https://doi.org/10.1016/j.jclepro. 2015.12.036

59. Dewulf J, Van Langenhove H, Muys B, Bruers S, Bakshi BR, Grubb GF et al (2008) Exergy: its potential and limitations in environmental science and technology. Environ Sci Technol 42:2221-2232. https://doi.org/10.1021/es071719a
60. Aghbashlo M, Mandegari M, Tabatabaei M, Farzad S, MojarabSoufiyan M, Görgens JF (2018) Exergy analysis of a lignocellulosic-based biorefinery annexed to a sugarcane mill for simultaneous lactic acid and electricity production. Energy 149:623-38. https://doi.org/10.1016/j.energy.2018.02.063

61. Fallahi A, Farzad S, Mohtasebi SS, Mandegari M, Görgens JF, Gupta VK, et al (2021) Sustainability assessment of sugarcane residues valorization to biobutadiene by exergy and exergoeconomic evaluation. Renewable and Sustainable Energy Reviews 147:111214. https://doi.org/10.1016/j.rser.2021.111214

62. Soltanian S, Aghbashlo M, Almasi F, Hosseinzadeh-Bandbafha H, Nizami AS, Ok YS et al (2020) A critical review of the effects of pretreatment methods on the exergetic aspects of lignocellulosic biofuels. Energy Convers Manag 212:112792. https://doi.org/10. 1016/j.enconman.2020.112792

63. Rösch C, Varela VJ (2021) Perception of EU citizens on engineered biocatalytic solar fuels. Renew Sustain Energy Rev 149:113. https://doi.org/10.1016/j.rser.2021.111366

64. Nilsson A, Shabestary K, Brandão M, Hudson EP (2020) Environmental impacts and limitations of third-generation biobutanol: life cycle assessment of n-butanol produced by genetically engineered cyanobacteria. J Ind Ecol 24:205-216. https://doi.org/10.1111/ jiec. 12843

Publisher's Note Springer Nature remains neutral with regard to jurisdictional claims in published maps and institutional affiliations. 